\title{
Risk of vertebral and non-vertebral fractures in patients with sarcoidosis: a population-based cohort
}

\author{
S. Bours ${ }^{1}$ • F. de Vries ${ }^{2,3,4,5,13}$ - J. P. W. van den Bergh ${ }^{7,8,9}$ - A. Lalmohamed ${ }^{2,10}$. \\ T. P. van Staa ${ }^{2,6}$ • H. G. M. Leufkens ${ }^{2}$ • P. P. P. Geusens ${ }^{1,9} \cdot$ M. Drent ${ }^{11,12}$ • N. C. Harvey ${ }^{3}$
}

Received: 15 July 2015 / Accepted: 13 November 2015 / Published online: 2 December 2015

(C) The Author(s) 2015. This article is published with open access at Springerlink.com

\begin{abstract}
Summary In this retrospective cohort study using the Clinical Practice Research Datalink (CPRD), patients with sarcoidosis have an increased risk of clinical vertebral fractures and when on recent treatment with oral glucocorticoids, also an increased risk of any fractures and osteoporotic fractures.

Introduction Sarcoidosis is a chronic inflammatory disease, in which fragility fractures have been reported despite normal BMD. The aim of this study was to assess whether patients with sarcoidosis have an increased risk of clinical fractures compared to the general population.

Methods A retrospective cohort study was conducted using the CPRD. All patients with a CPRD code for sarcoidosis between January 1987 and September 2012 were included. Cox proportional hazards models were used to derive adjusted relative risks (RRs) of fractures in all sarcoidosis patients compared to matched controls, and within the sarcoidosis group according to use and dose of systemic glucocorticoids.
\end{abstract}

F. de Vries

f.devries@uu.nl

1 Department of Internal Medicine, Subdivision of Rheumatology, Maastricht University Medical Centre, Maastricht, The Netherlands

2 Division of Pharmacoepidemiology and Clinical Pharmacology, Utrecht Institute of Pharmaceutical Sciences, Utrecht, The Netherlands

3 MRC Lifecourse Epidemiology Unit, University of Southampton, Southampton General Hospital, Southampton, UK

4 Department of Clinical Pharmacy and Toxicology, Maastricht University Medical Centre, Maastricht, The Netherlands

5 CAPHRI School for Public Health and Primary Care, Maastricht University, Maastricht, The Netherlands

6 Farr Institute, University of Manchester, Manchester, UK
Results Five thousand seven hundred twenty-two sarcoidosis patients (mean age 48.0 years, $51 \%$ females, mean follow-up 6.7 years) were identified.

Compared to 28,704 matched controls, the risk of any fracture was not different in patients with sarcoidosis. However, the risk of clinical vertebral fractures was significantly increased (adj RR 1.77; $95 \%$ CI 1.06-2.96) and the risk of non-vertebral fractures was decreased although marginally significant (adj RR 0.87; $95 \%$ CI 0.77-0.99). Compared to sarcoidosis patients not taking glucocorticoids, recent use of systemic glucocorticoids was associated with an increased risk of any fracture (adj RR 1.50; $95 \%$ CI 1.20-1.89) and of an osteoporotic fracture (adj RR 1.47; 95 \% CI 1.07-2.02).

Conclusions Patients with sarcoidosis have an increased risk of clinical vertebral fractures, and when using glucocorticoid therapy, an increased risk of any fractures and osteoporotic fractures. In contrast, the risk of nonvertebral fractures maybe decreased. Further investigation

7 Department of Internal Medicine, Viecuri MC Venlo, Venlo, The Netherlands

8 NUTRIM School of Nutrition and Translational Research in Metabolism, Maastricht University, Maastricht, The Netherlands

9 Biomedical Research Institute, Hasselt University, Hasselt, Belgium

10 Department of Clinical Pharmacy, University Medical Center Utrecht, Utrecht, The Netherlands

11 ILD Center of Excellence, St. Antonius Hospital, Nieuwegein, The Netherlands

12 Department of Pharmacology and Toxicology, FHML, University Maastricht, Maastricht, The Netherlands

13 Division of Pharmacoepidemiology and Clinical Pharmacology, Utrecht Institute for Pharmaceutical Sciences, Utrecht University, Utrecht, The Netherlands 
is needed to understand the underlying mechanisms of these contrasting effects on fracture risk.

Keywords Bone $\cdot$ Epidemiology $\cdot$ Fractures ·

Glucocorticoids · Osteoporosis · Sarcoidosis

\section{Introduction}

Sarcoidosis is a multi-organ, chronic inflammatory, granulomatous disorder that can affect almost any organ of the body. It may occur at any age, but most frequently in adults younger than 50 years. It is more common in women and certain racial groups, such as African-Americans and northern Europeans [1-4]. Around 300-400 new cases of sarcoidosis are diagnosed per year in the UK [5].

Bone mineral density (BMD) is decreased and the risk of clinical and radiological vertebral fractures is increased in chronic inflammatory diseases such as asthma and chronic obstructive pulmonary disease (COPD) [6, 7], rheumatoid arthritis [8-10], ankylosing spondylitis [11, 12], systemic lupus erythematosus [13], and inflammatory bowel disease [14]. In addition, treatment with glucocorticoids has been associated with a dose-dependent increase in fracture risk [9, 15-17], at a higher level of BMD than in patients who do not use glucocorticoids.

In patients with sarcoidosis, small cohort studies have demonstrated a high prevalence of fragility fractures $(23.5 \%)$ [18] and radiographic vertebral fractures (20-30\%) [19], with an increase of incidence (up to $32 \%$ ) of vertebral fractures during follow-up [20]. In contrast, BMD has been found to be normal in most patients with sarcoidosis [19, 21-24] and BMD did not change over time [20,25]. Furthermore, the effect of glucocorticoids on bone might be reversible [26, 27]. No studies are available that investigated the prevalence of vertebral and non-vertebral fractures in patients with sarcoidosis compared to a control population and the effect of glucocorticoid therapy on fracture risk in sarcoidosis.

The first objective of this study is to determine whether patients with sarcoidosis have an increased risk of clinical fractures compared to the general population. The second objective is to estimate their fracture risk, stratified by glucocorticoid use.

\section{Methods}

\section{Source population}

A retrospective cohort study was conducted using the Clinical Practice Research Datalink (CPRD), formerly known as the General Practice Research Database. The CPRD contains computerized medical records of 625 primary care practices in the UK, representing $8 \%$ of the British population. The database provides detailed information on demographics, drug prescriptions, clinical events, specialist referrals, and hospital admissions. Previous studies of CPRD data have shown a high level of data validity with respect to the reporting of fractures $(>90 \%$ of fractures were confirmed) [16]. The protocol number is 2010_060.

\section{Study population}

All patients with a CPRD read code for sarcoidosis during the study period (from January 1987 through September 2012) were included in the study population. In order to ascertain a more probable diagnosis of sarcoidosis, these patients were stratified into probable and possible cases of sarcoidosis. Probable cases had at least one sarcoidosis CPRD record and any of the following: (1) treatment with methotrexate, azathioprine, leflunomide, chloroquine, hydroxychloroquine, and systemic/inhaled glucocorticoids at any time during follow-up, (2) two or more subsequent diagnoses of sarcoidosis, and/or (3) a specialist diagnosis of sarcoidosis. All other sarcoidosis patients were defined as possible cases. The index date was defined as the first record for sarcoidosis. Each patient was matched by age, sex, calendar time, and practice to up to four patients without a history of sarcoidosis ever during the study period.

\section{Outcomes}

All patients had a follow-up from the index date to either the end of data collection, the date of transfer of the patient out of the practice area, the patient's death, or fracture (GPRD read codes), whichever came first.

Earlier studies have demonstrated that there is a high level of data validity with respect to reporting of fractures from CPRD databases and $>90 \%$ of reported fractures were confirmed [16].

The primary outcome of this study was to determine whether patients with sarcoidosis have an increased risk of clinical fractures compared to the general population. For additional analyses, fracture type was stratified according to the WHO Fracture Risk Assessment Tool into osteoporotic (spine, hip, forearm, or humerus fracture), and non-osteoporotic fractures (all other fractures) and also stratified into vertebral and non-vertebral fractures. The second objective was to estimate their fracture risk, stratified by glucocorticoid use.

\section{Potential confounders}

Total follow-up was divided into 30-day intervals. Before the start of each 30-day interval, the presence of general risk factors for fracture was evaluated. At 
baseline, information was available about age, sex, smoking status, body mass index, alcohol use, a record of falls in the previous 6-12 months, and a history of fracture. Furthermore, we assessed if there was a history of a chronic disease (rheumatoid arthritis, cerebrovascular disease, heart failure, inflammatory bowel disease, asthma/chronic obstructive pulmonary disease, secondary osteoporosis, anaemia, and dementia). Prescriptions for glucocorticoids (systemic and local separately), hypnotic/anxiolytic, antipsychotic, antidepressant, proton pump inhibitor, antidiabetic, or antiepileptic agents, as well as drugs for the treatment of Parkinson's disease, in the 6 months before inclusion, were recorded.

For each sarcoidosis patient, the use of systemic glucocorticoids in the previous 6 months before inclusion was evaluated. Systemic glucocorticoid users were further stratified according to their average and cumulative dose using the World Health Organisation's defined daily dosages (DDD) [28]. Exposure was expressed as oral prednisone equivalents. For the cumulative exposure, all prescriptions of the most recent treatment period (allowing a maximum non-use gap of 6 months between two prescriptions) were considered. For the average daily dose, the cumulative exposure of the most recent treatment period was divided by the number of days between start and end of the treatment period. When data on the prescribed quantity were missing, the median expected quantity was used.

\section{Statistical analysis}

Cox proportional hazards models were used to derive adjusted relative risks (adj RRs) for fracture (any, osteoporotic, and non-osteoporotic) in sarcoidosis patients compared with matched control subjects (SAS 9.2, PHREG procedure). Potential confounders were entered into the final model if they independently changed the beta coefficient by at least $5 \%$. This main analysis was repeated for possible and probable cases of sarcoidosis. For all other analyses, the full cohort of sarcoidosis patients (probable and possible cases) was used. Within sarcoidosis patients, the individuals were stratified according to their cumulative and average daily dose of systemic glucocorticoid exposure. Furthermore, absolute incidence rates for fractures in sarcoidosis patients and matched controls were calculated.

Timing of fracture occurrence following first sarcoidosis record was examined by including time interaction terms into the model for the following time intervals: $<6$ months, 6-12 months, 1-2 years, 2-5 years, 5-10 years, and $>10$ years. Using smoothing spline regression, the time trend for risk of fracture for these given time intervals was visualized.

\section{Results}

We identified 5722 sarcoidosis patients along with 28,704 age- and sex-matched controls (mean age 48.0 years, $51 \%$ females), with a mean follow-up of 6.7 years per patient. Baseline characteristics of patients with sarcoidosis and ageand sex-matched controls are shown in Table 1. There were substantially fewer smokers among the sarcoidosis patients than in the matched controls (current smokers 13.8 vs. $25.4 \%$ ). Furthermore, patients with sarcoidosis were more likely to have used medical drugs in the previous 6 months, in particular systemic/local glucocorticoids, antidiabetics, antidepressants, benzodiazepines, and calcium/vitamin D supplements. Bisphosphonate use was higher among sarcoidosis patients $(4.3 \%)$ compared to matched controls $(1.0 \%)$, whereas no differences were observed for use of HRT and other antiosteoporotic drugs.

In the sarcoidosis cohort, 406 patients had at least one fracture; 203 osteoporotic fractures occurred (37 clinical vertebral fractures, 22 hip fractures, 144 other osteoporotic fractures, i.e., forearm or humerus fractures) and 263 nonosteoporotic fractures (Table 2). There was no difference between patients with sarcoidosis and matched controls in the risk of any fracture (adj RR 0.90; $95 \%$ CI 0.80-1.02), an osteoporotic fracture (adj RR 1.02, $95 \%$ CI $0.85-1.23$ ) or non-osteoporotic fracture (adj RR 0.89, $95 \%$ CI 0.76-1.03). Further adjustments for antiosteoporotic drugs did not alter the relative risk estimates (e.g., for any fracture: HR 0.91 (95\% CI 0.81-1.03). The risk of clinical vertebral fractures was significantly increased in patients with sarcoidosis (adj RR 1.77; $95 \%$ CI 1.06-2.96), and the risk for non-vertebral fractures was decreased (adj RR 0.87; $95 \%$ CI 0.77-0.99).

The adj RR was not modified by the sarcoidosis case definition (possible sarcoidosis: adj RR 0.92; $95 \%$ CI 0.76-1.13; probable sarcoidosis: adj RR 0.89; $95 \%$ CI 0.76-1.04 for any fracture) and there was no statistical interaction with age, sex, or type of fracture. When plotted against time since diagnosis, the risk of any fracture was temporarily decreased during the first years after diagnosis, but was not different during longer follow-up (Fig. 1).

Use of systemic glucocorticoids in the previous 6 months increased the risk of any facture (adj RR 1.50; $95 \%$ CI 1.201.89 ) and of an osteoporotic fracture (adj RR 1.47; $95 \% \mathrm{CI}$ 1.07-2.02) compared to no use of systemic glucocorticoids (Table 3). The risk of any fracture and of an osteoporotic fracture increased already with a daily dose of $<5 \mathrm{mg}$ prednisone equivalents per day (adj RR 1.49; $95 \%$ CI 1.12-1.97 and adj RR 1.52; $95 \%$ CI 1.04-2.23 for any and osteoporotic fracture, respectively) and with the lowest cumulative doses (<1820 mg; adj RR 1.67; $95 \%$ CI 1.08-2.59 and adj RR 2.02; $95 \%$ CI 1.14-3.59 for any and osteoporotic fracture, respectively). The fracture risk did not increase significantly with higher dose or higher cumulative dose. 
Table 1 Baseline characteristics of sarcoidosis patients and matched controls

\begin{tabular}{|c|c|c|c|c|}
\hline \multirow[t]{2}{*}{ Characteristic } & \multicolumn{2}{|c|}{ Sarcoidosis patients } & \multicolumn{2}{|c|}{ Matched controls } \\
\hline & $N=5722$ & Percent & $N=28,704$ & Percent \\
\hline Follow-up (years, mean, SD) & $6.7(5.2)$ & & $6.7(5.2)$ & \\
\hline Females & 2918 & $(51.0)$ & 14,637 & $(51.0)$ \\
\hline Age (years, mean, SD) & $48.0(13.4)$ & & $48.0(13.4)$ & \\
\hline $18-39$ years & 1691 & $(29.6)$ & 8479 & $(29.5)$ \\
\hline $40-59$ years & 2847 & $(49.8)$ & 14,284 & $(49.8)$ \\
\hline $60-79$ years & 1115 & $(19.5)$ & 5598 & $(19.5)$ \\
\hline $80+$ years & 69 & $(1.2)$ & 343 & $(1.2)$ \\
\hline BMI $\left(\mathrm{kg} / \mathrm{m}^{2}\right.$, mean, $\left.\mathrm{SD}\right)$ & $27.9(5.9)$ & & $26.8(5.4)$ & \\
\hline$<20.0 \mathrm{~kg} / \mathrm{m}^{2}$ & 232 & $(4.1)$ & 1301 & $(4.5)$ \\
\hline $20-24.9 \mathrm{~kg} / \mathrm{m}^{2}$ & 1468 & $(25.7)$ & 8745 & $(30.5)$ \\
\hline $25.0-29.9 \mathrm{~kg} / \mathrm{m}^{2}$ & 1943 & $(34.0)$ & 8614 & $(30.0)$ \\
\hline $30.0+\mathrm{kg} / \mathrm{m}^{2}$ & 1505 & $(26.3)$ & 5538 & $(19.3)$ \\
\hline Unknown & 574 & $(10.0)$ & 4506 & $(15.7)$ \\
\hline \multicolumn{5}{|l|}{ Smoking status } \\
\hline Never & 3763 & $(65.8)$ & 15,215 & $(53.0)$ \\
\hline Current & 792 & $(13.8)$ & 7304 & $(25.4)$ \\
\hline Ex & 1041 & $(18.2)$ & 4537 & $(15.8)$ \\
\hline Unknown & 126 & $(2.2)$ & 1648 & $(5.7)$ \\
\hline \multicolumn{5}{|l|}{ Alcohol use } \\
\hline No & 1104 & $(19.3)$ & 4210 & $(14.7)$ \\
\hline Yes & 3973 & $(69.4)$ & 19,972 & $(69.6)$ \\
\hline Unknown & 645 & $(11.3)$ & 4522 & $(15.8)$ \\
\hline Falls (6-12 months before) & 230 & $(4.0)$ & 1050 & $(3.7)$ \\
\hline Fracture ever before & 1079 & $(18.9)$ & 5096 & $(17.8)$ \\
\hline \multicolumn{5}{|l|}{ History of disease } \\
\hline Rheumatoid arthritis & 79 & $(1.4)$ & 238 & $(0.8)$ \\
\hline Cerebrovascular disease & 111 & $(1.9)$ & 452 & (1.6) \\
\hline Inflammatory bowel disease & 87 & $(1.5)$ & 237 & $(0.8)$ \\
\hline COPD & 157 & $(2.7)$ & 381 & (1.3) \\
\hline Asthma & 923 & $(16.1)$ & 3008 & $(10.4)$ \\
\hline Hypertension & 900 & $(15.7)$ & 3784 & $(13.2)$ \\
\hline Dementia & 21 & $(0.4)$ & 70 & $(0.2)$ \\
\hline Heart failure & 98 & $(1.7)$ & 199 & $(0.7)$ \\
\hline \multicolumn{5}{|l|}{ Drug use within 6 months } \\
\hline Systemic glucocorticoids & 953 & $(16.7)$ & 492 & $(1.7)$ \\
\hline Topical glucocorticoids & 618 & $(10.8)$ & 1782 & $(6.2)$ \\
\hline Antidiabetics & 263 & $(4.6)$ & 810 & $(2.8)$ \\
\hline Anticonvulsants & 166 & $(2.9)$ & 467 & $(1.6)$ \\
\hline Loop diuretics & 294 & $(5.1)$ & 568 & $(2.0)$ \\
\hline Proton pump inhibitors & 825 & $(14.4)$ & 1869 & $(6.5)$ \\
\hline Antipsychotics & 59 & $(1.0)$ & 298 & $(1.0)$ \\
\hline Antidepressants & 658 & $(11.5)$ & 2418 & $(8.4)$ \\
\hline Anxiolytics/hypnotics & 360 & $(6.3)$ & 1166 & $(4.1)$ \\
\hline Calcium/vitamin D & 251 & $(4.4)$ & 412 & (1.4) \\
\hline Bisphosphonates & 254 & $(4.3)$ & 283 & $(1.0)$ \\
\hline Hormone replacement therapy & 206 & (3.6) & 1093 & $(3.8)$ \\
\hline Other antiosteoporotic drugs & 1 & $(0.0)$ & 6 & $(0.0)$ \\
\hline
\end{tabular}

$B M I$ body mass index, $S D$ standard deviation 
Table 2 Risk of fracture in sarcoidosis patients compared with matched controls, stratified by age, sex, and type of fracture

\begin{tabular}{|c|c|c|c|c|}
\hline & \multirow[t]{2}{*}{ Person years } & \multicolumn{3}{|c|}{ Fracture } \\
\hline & & Events & Age-sex adj RR $(95 \% \mathrm{CI})$ & Adj RR (95\% CI) (a) \\
\hline No sarcoidosis & 183,514 & 1815 & Reference & Reference \\
\hline \multicolumn{5}{|l|}{ Sarcoidosis } \\
\hline Any fracture & 36,760 & 406 & $1.14(1.02-1.27)$ & $0.90(0.80-1.02)$ \\
\hline \multicolumn{5}{|l|}{ By age (years) } \\
\hline $18-39$ & 7384 & 48 & $0.67(0.49-0.91)$ & $0.60(0.42-0.85)$ \\
\hline $40-59$ & 19,763 & 171 & $1.17(0.99-1.39)$ & $0.95(0.78-1.15)$ \\
\hline $60-79$ & 9012 & 166 & $1.41(1.18-1.68)$ & $1.07(0.87-1.31)$ \\
\hline $80+$ & 601 & 21 & $1.07(0.64-1.78)$ & $0.97(0.56-1.67)$ \\
\hline \multicolumn{5}{|l|}{ By sex } \\
\hline Males & 17,529 & 143 & $0.98(0.81-1.18)$ & $0.79(0.64-0.97)$ \\
\hline Females & 19,231 & 263 & $1.24(1.08-1.43)$ & $0.97(0.83-1.13)$ \\
\hline Osteoporotic fracture & 37,670 & 203 & $1.37(1.17-1.60)$ & $1.02(0.85-1.23)$ \\
\hline Hip fracture & 38,397 & 22 & $0.93(0.59-1.48)$ & $0.61(0.35-1.04)$ \\
\hline Vertebral fracture $^{\mathrm{a}}$ & 38,363 & 37 & $3.10(2.04-4.70)$ & $1.77(1.06-2.96)$ \\
\hline Non-osteoporotic fracture & 37,256 & 263 & $1.07(0.93-1.23)$ & $0.89(0.76-1.03)$ \\
\hline Non-vertebral fracture ${ }^{\mathrm{a}}$ & 36,852 & 377 & $1.08(0.96-1.21)$ & $0.87(0.77-0.99)$ \\
\hline
\end{tabular}

Adjusted for smoking status, a history of heart failure, asthma/COPD, and use of systemic glucocorticoids, calcium/vitamin D supplements, loop diuretics, benzodiazepines, antidepressants, proton pump inhibitors, and anticonvulsants in the previous 6 months

Adj adjusted, $C I$ confidence interval, $R R$ relative risk

${ }^{a}$ There were eight patients that sustained both a vertebral and non-vertebral fracture

\section{Discussion}

In this large population-based study, patients with sarcoidosis had an increased risk of clinical vertebral fractures compared to matched controls and, when on recent therapy with systemic glucocorticoids, an increased risk of any fractures and osteoporotic fractures. In contrast, the risk of non-vertebral fractures was decreased, although marginally significant. To our knowledge, this study is the first population-based study that assessed vertebral and non-vertebral fracture risk in patients with sarcoidosis compared to matched control subjects.

The risk of clinical vertebral fractures was increased, which is in line with findings in other inflammatory diseases such as rheumatoid arthritis [9, 29, 30], ankylosing spondylitis $[11,12]$, SLE $[13,31]$, COPD [6, 7] and inflammatory bowel disease [14]. Possible explanations for the increased vertebral fracture risk can be found in other studies regarding patients with sarcoidosis, such as the finding of a decreased trabecular BMD within the vertebrae [26], a decreased BMD in the spine in postmenopausal women [22], and an increased bone resorption [19]. In spite of the increased risk of clinical vertebral fractures in patients with sarcoidosis, the total number of vertebral fractures was low. This is in contrast with other studies in patients with sarcoidosis where vertebral fractures were assessed by systemic radiographic evaluation $[19,20]$, suggesting that most radiographic vertebral fractures are not accompanied by typical signs and symptoms of an acute vertebral fracture. This is also the case for vertebral fractures in postmenopausal osteoporosis $[32,33]$.

The decreased adjusted risk of non-vertebral fractures in our study is an unexpected finding and only marginally statistically significant. It is in contrast with the increased risk of

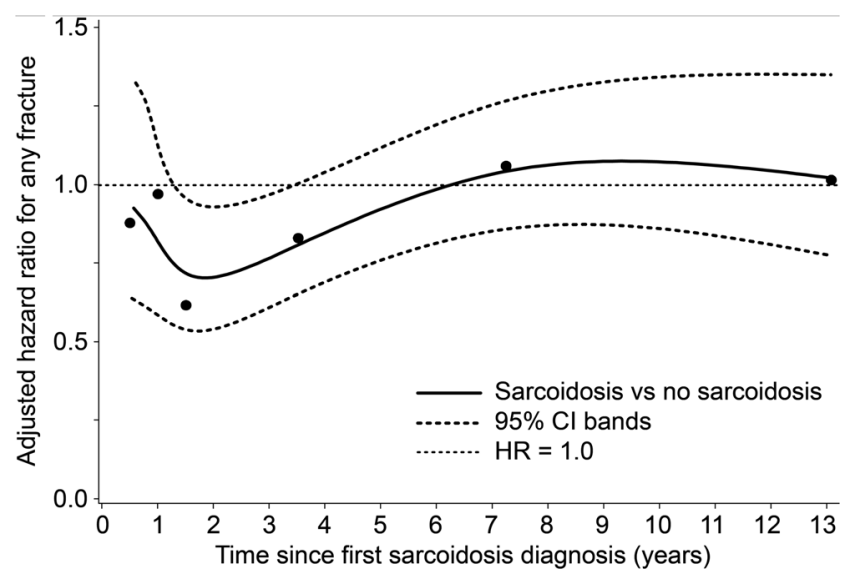

Fig. 1 Spline regression plot of time since first sarcoidosis record and risk of any fracture in sarcoidosis patients versus matched controls. Adjusted for confounders as shown in Table 2 
Table 3 Risk of any and osteoporotic fractures within sarcoidosis patients, stratified by use of drugs

\begin{tabular}{|c|c|c|c|c|}
\hline & \multicolumn{2}{|c|}{ Any fracture } & \multicolumn{2}{|c|}{ Osteoporotic fracture } \\
\hline & Events & Adj RR $(95 \% \mathrm{CI})^{\mathrm{a}}$ & Events & Adj RR $(95 \% \mathrm{CI})^{\mathrm{a}}$ \\
\hline \multicolumn{5}{|c|}{ By use of systemic glucocorticoids in the previous 6 months (reference $=$ no use) ${ }^{b}$} \\
\hline No & 263 & 1.00 & 126 & 1.00 \\
\hline Yes & 143 & $1.50(1.20-1.89)$ & 77 & $1.47(1.07-2.02)$ \\
\hline \multicolumn{5}{|c|}{ By average daily dose of systemic glucocorticoid exposure in the previous year, expressed as prednisone equivalents } \\
\hline$\leq 5 \mathrm{mg}^{\mathrm{c}}$ & 66 & $1.49(1.12-1.97)$ & 37 & $1.52(1.04-2.23)$ \\
\hline $5.1-10 \mathrm{mg}$ & 45 & $1.36(0.97-1.90)$ & 21 & $1.13(0.69-1.84)$ \\
\hline$>10 \mathrm{mg}$ & 32 & $1.88(1.26-2.79)$ & 19 & $2.09(1.24-3.53)$ \\
\hline \multicolumn{5}{|c|}{ By cumulative dose of systemic glucocorticoid exposure, expressed as prednisone equivalents ${ }^{\mathrm{d}}$} \\
\hline$<1820 \mathrm{mg}^{\mathrm{c}}$ & 22 & $1.67(1.08-2.59)$ & 13 & $2.02(1.14-3.59)$ \\
\hline $1820-7300 \mathrm{mg}$ & 41 & $1.37(0.97-1.93)$ & 22 & $1.36(0.85-2.17)$ \\
\hline$>7300 \mathrm{mg}$ & 80 & $1.53(1.16-2.03)$ & 42 & $1.39(0.94-2.04)$ \\
\hline \multicolumn{5}{|c|}{ By use of antidepressants in the previous 6 months (reference-no use) ${ }^{\mathrm{b}}$} \\
\hline No & 318 & 1.00 & 157 & 1.00 \\
\hline Yes & 88 & $1.25(0.97-1.61)$ & 46 & $1.08(0.76-1.55)$ \\
\hline \multicolumn{5}{|c|}{ By use of anxiolytics/hypnotics in the previous 6 months (reference $=$ no use) ${ }^{\mathrm{b}}$} \\
\hline No & 364 & 1.00 & 176 & 1.00 \\
\hline Yes & 42 & $1.16(0.83-1.63)$ & 27 & $1.37(0.89-2.12)$ \\
\hline
\end{tabular}

Adj adjusted, $C I$ confidence interval, $R R$ relative risk

${ }^{a}$ Adjusted for confounders shown in footnote Table 2

${ }^{\mathrm{b}}$ Reference $=$ no use in the previous 6 months

${ }^{\mathrm{c}}$ Excluding no use of systemic glucocorticoids in the previous 6 months

${ }^{\mathrm{d}}$ Cumulative amount of all previous systemic glucocorticoid prescriptions

vertebral fractures in this study and with the increased risk of non-vertebral fractures in inflammatory rheumatic diseases such as rheumatoid arthritis $[9,34,35]$, ankylosing spondylitis [36], and JIA [36]. Another study did find a high fracture incidence in patients with sarcoidosis [18]. However, in the latter study there was no control population, and the study population consisted of patients at a pulmonary outpatient clinic where $62.0 \%$ of patients were treated with glucocorticoids (vs. $16.7 \%$ in our study). In most studies in patients with sarcoidosis, BMD was normal in all patients $[18,19,21,23$, $24]$ even in those treated with glucocorticoids [18, 19], with the exception of one study that showed a decreased BMD in postmenopausal but not in premenopausal women [22]. Why BMD in the spine and hip is normal in most patients with sarcoidosis, is unclear and it does not explain the slightly decreased risk of non-vertebral fractures in patients with sarcoidosis compared to matched controls.

The increased risk of any and of osteoporotic fractures in patients with recent use of systemic glucocorticoids is in line with findings of increased fracture risk in glucocorticoid users in other inflammatory diseases [15-17]. However, we did not find a further increase in fracture risk with higher daily or cumulative doses of glucocorticoids. Treatment of inflammatory diseases for example rheumatoid arthritis results in lower disease activity and adequate disease control which contributes to bone protection, even when glucocorticoids are used [37]. The time relation between onset of sarcoidosis and initial but not persisting decrease of risk of any fracture indicates that disease or treatment related factors early in the disease could play a protective role on non-vertebral fracture risk.

In population-based cohort studies, a relation between CRP and fracture risk has been reported even after adjustment for confounding factors [38-40], however this relation could be U-shaped [41] or only present when CRP was $>3 \mathrm{mg} / 1$ [42, 43]. In patients with sarcoidosis, however, no correlation was found between bone turnover markers or CRP and BMD or fractures [18]. In our study, we did not have additional information on markers for inflammation (IL2R, ACE) or disease activity.

Other factors, such as low dietary calcium intake, low creatinine clearance, and higher $25(\mathrm{OH}) \mathrm{D}$ and $1,25(\mathrm{OH})$ are associated to an increased fracture risk and bone resorption in sarcoidosis $[18,44]$, but no data were available on these parameters in our study. Besides BMD and bone-related risk factors, other factors could influence fracture risk in patients with sarcoidosis. Patients with sarcoidosis have an increased risk of sarcopenia, which could increase the risk of falls and bone loss [45]. We did not have information on diagnostic 
tests for sarcopenia, such as muscle strength and mass. Body mass index (BMI) in patients with sarcoidosis was not different compared to controls. Sarcoidosis can also be localised in bone, as has been demonstrated by a study with PET scans which show extensive bone marrow involvement in sarcoidosis [46]. Sarcoid granulomas are surrounded by osteoclasts, but a local focus of osseous sarcoidosis resulting in a fracture is rare [47]. Pulmonary Wnt signalling is altered in patients with sarcoidosis [48]; however, whether Wnt signalling in bone is also altered in patients with sarcoidosis is unknown.

The fact that the risk of clinical vertebral fractures was increased, whereas the risk of all fractures was not different compared to matched controls, suggests that sarcoidosis probably has a negative impact on the trabecular bone without affecting the cortical bone. The finding of a decreased risk of non-vertebral fractures in this study was only marginally significant and in combination with data from literature the question is whether non-vertebral fracture risk is actually decreased in patients with sarcoidosis.

Limitations of our study were the lack of information on markers for inflammation (IL2R, ACE), disease activity, and BMD, so we could not adjust for these possible confounders. In addition, no information was available on muscle strength or mass and fall risk. The sarcoidosis case definition was described, but we were not able to confirm the diagnosis based on direct data from rheumatologists, pulmonologists, or other physicians.

In conclusion, patients with sarcoidosis have an increased risk of clinical vertebral fractures, and when on recent treatment with oral glucocorticoids, also an increased risk of any fractures and osteoporotic fractures. The decreased risk of non-vertebral fractures was an intriguing and unexpected finding, however with marginal statistical significance, and further studies should be performed to understand more about the factors that could protect against bone loss and non-vertebral fracture risk in sarcoidosis.

\section{Compliance with ethical standards}

Conflicts of interest The Division of Pharmacoepidemiology and Clinical Pharmacology, Utrecht Institute for Pharmaceutical Sciences, employing authors AL, TvS, HL, and FdV has received unrestricted research funding from the Netherlands Organisation for Health Research and Development (ZonMW), the Dutch Health Care Insurance Board (CVZ), the Royal Dutch Pharmacists Association (KNMP), the private-public funded Top Institute Pharma (www.tipharma.nl, includes co-funding from universities, government, and industry), the EU Innovative Medicines Initiative (IMI), EU Seventh Framework Program (FP7), the Dutch Medicines Evaluation Board, and the Dutch Ministry of Health and industry (including GlaxoSmithKline, Pfizer, and others). NH has received consultancy, lecture fees, and honoraria from Alliance for Better Bone Health, AMGEN, MSD, Eli Lilly, Servier, Shire, Consilient Healthcare, and Internis Pharma.

Open Access This article is distributed under the terms of the Creative Commons Attribution-NonCommercial 4.0 International License (http:// creativecommons.org/licenses/by-nc/4.0/), which permits any noncommercial use, distribution, and reproduction in any medium, provided you give appropriate credit to the original author(s) and the source, provide a link to the Creative Commons license, and indicate if changes were made.

\section{References}

1. Dempsey O, Paterson, EW, Kerr, KM, Denison, AR (2009) Sarcoidosis. BMJ 339. doi: 10.1136/bmj.b3206

2. Valeyre D, Prasse A, Nunes H, Uzunhan Y, Brillet PY, MüllerQuernheim J (2014) Sarcoidosis. Lancet 383:1155-1167

3. Iannuzzi MC, Fontana JR (2011) Sarcoidosis: clinical presentation, immunopathogenesis, and therapeutics. JAMA 305(4):391-399. doi:10.1001/jama.2011.10

4. Joint Statement of the American Thoracic Society (ATS), the European Respiratory Society (ERS) and the World Association of Sarcoidosis and Other Granulomatous Disorders (WASOG) adopted by the ATS Board of Directors and by the ERS Executive Committee, February 1999 (1999) Statement on sarcoidosis. Am J Respir Crit Care Med 160(2):736-755

5. Gribbin J, Hubbard RB, Le Jeune I, Smith CJ, West J, Tata LJ (2006) Incidence and mortality of idiopathic pulmonary fibrosis and sarcoidosis in the UK. Thorax 61(11):980-985

6. De Vries F, Van Staa TP, Bracke MS, Cooper C, Leufkens HG, Lammers JW (2005) Severity of obstructive airway disease and risk of osteoporotic fracture. Eur Respir J 25(5):879-884

7. Romme E, Smeenk FW, Rutten EP, Wouters EF (2013) Osteoporosis in chronic obstructive pulmonary disease. Expert Rev Respir Med 7(4):397-410. doi:10.1586/17476348.2013. 814402

8. Dirven L, van den Broek M, van Groenendael JH et al (2012) Prevalence of vertebral fractures in a disease activity steered cohort of patients with early active rheumatoid arthritis. BMC Musculoskelet Disord 13:125

9. Van Staa T, Geusens P, Bijlsma JW, Leufkens HG, Cooper C (2006) Clinical assessment of the long-term risk of fracture in patients with rheumatoid arthritis. Arthritis Rheum 54(10):3104-3112

10. Mohammad A, Lohan D, Bergin D et al. (2013) The prevalence of vertebral fracture on vertebral fracture assessment imaging in a large cohort of patients with rheumatoid arthritis.doi:10.1093/ rheumatology/ket353.

11. Vosse D, Landewé R, Van der Heijde D et al (2009) Ankylosing spondylitis and the risk of fracture: results from a large primary care-based nested case control study. Ann Rheum Dis 68:1839-1842

12. Sambrook P, Geusens P (2012) The epidemiology of osteoporosis and fractures in ankylosing spondylitis. Ther Adv Musculoskel Dis 4:4

13. Almehed K, Hetényi, S, Ohlsson, C, et al. (2010) Prevalence and risk factors of vertebral compression fractures in female SLE patients. Arthritis Res Ther 12

14. Vázquez A, Lopez, E, Montoya J et al. (2012) Vertebral fractures in patients with inflammatory bowel disease compared with a healthy population: a prospective case-control study. BMC Gastroenterol 12

15. De Vries F, Bracke M, Leufkens HG, Lammers JW, Cooper C, Van Staa TP (2007) Fracture risk with intermittent high-dose oral glucocorticoid therapy. Arthritis Rheum 56(1):208-214

16. Van Staa T, Abenhaim L, Cooper C, Zhang B, Zhang B, Leufkens HGM (2000) The use of a large pharmacoepidemiological database to study exposure to oral corticosteroids and risk of fractures: validation of study population and results. Pharmacoepidemiol Drug Saf 9:359-366 
17. van Staa TPLH, Abenhaim L, Zhang B, Cooper C (2000) Oral corticosteroids and fracture risk: relationship to daily and cumulative doses. Rheumatology (Oxford) 39(12):1383-1389

18. Saidenberg-Kermanac'h N, Semerano L, Nunes H, Sadoun D, Guillot X, Boubaya M, Naggara N, Valeyre D, Boissier MC (2014) Bone fragility in sarcoidosis and relationships with calcium metabolism disorders: a cross sectional study on 142 patients. Arthritis Res Ther 16:R78. doi:10.1186/ar4519

19. Heijckmann A, Huijberts MS, De Vries J, Menheere PP, Van Der Veer E, Kruseman AC, Wolffenbuttel BH, Geusens P, Drent M (2007) Bone turnover and hip bone mineral density in patients with sarcoidosis. Sarcoidosis Vasc Diffuse Lung Dis 24(1):51-58

20. Heijckmann A, Drent M, Dumitrescu B, De Vries J, Nieuwenhuijzen Kruseman AC, Wolffenbuttel BH, Geusens P, Huijberts MS (2008) Progressive vertebral deformities despite unchanged bone mineral density in patients with sarcoidosis: a 4-year follow-up study. Osteoporos Int 19(6):839-847. doi:10.1007/ s00198-007-0513-y

21. Tervonen S, Karjalainen P, Valta R (1974) Bone mineral in sarcoidosis. Acta Med Scand 196(6):497-503

22. Sipahi S, Tuzun S, Ozaras R, Calis HT, Ozaras N, Tuzun F, Karayel $\mathrm{T}$ (2004) Bone mineral density in women with sarcoidosis. J Bone Miner Metab 22(1):48-52

23. Montemurro L, Fraioli P, Rizzato G (1991) Bone loss in untreated longstanding sarcoidosis. Sarcoidosis 8(1):29-34

24. Rottoli P, Gonnelli S, Silitro S, Zacchei F, Fabbrini D, Gennari C, Vagliasindi M (1993) Alterations in calcium metabolism and bone mineral density in relation to the activity of sarcoidosis. Sarcoidosis 10(2):161-162

25. Bolland M, Wilsher ML, Grey A, Horne AM, Fenwick S, Gamble GD, Reid IR 2013 Randomised controlled trial of vitamin D supplementation in sarcoidosis. BMJ Open 3(10). doi: 10.1136/ bmjopen-2013-003562.

26. Rizzato GFP (1990) Natural and corticosteroid-induced osteoporosis in sarcoidosis: prevention, treatment, follow up and reversibility. Sarcoidosis 7:89-92

27. Rizzato G, Montemurro L (1993) Reversibility of exogenous corticosteroid-induced bone loss. Eur Respir J 6:116-119

28. Doherty DA, Sanders KM, Kotowicz MA, Prince RL (2001) Lifetime and five-year age-specific risks of first and subsequent osteoporotic fractures in postmenopausal women. Osteoporos Int $12: 16-23$

29. Amin S, Gabriel SE, Achenbach SJ, Atkinson EJ, Melton LJ 3rd (2013) Are young women and men with rheumatoid arthritis at risk for fragility fractures? A population-based study. J Rheumatol 40(10):1669-1676. doi:10.3899/jrheum.121493

30. Ghazi M, Kolta S, Briot K, Fechtenbaum J, Paternotte S, Roux C (2012) Prevalence of vertebral fractures in patients with rheumatoid arthritis: revisiting the role of glucocorticoids. Osteoporos Int 23(2): 581-587. doi:10.1007/s00198-011-1584-3

31. Bultink IE, Harvey NC, Lalmohamed A, Cooper C, Lems WF, van Staa TP, de Vries F (2014) Elevated risk of clinical fractures and associated risk factors in patients with systemic lupus erythematosus versus matched controls: a population-based study in the United Kingdom. Osteoporos Int 25(4):1275-1283. doi:10.1007/s00198$013-2587-\mathrm{z}$

32. Lems WF (2007) Clinical relevance of vertebral fractures. Ann Rheum Dis 66(1):2-4

33. Jager PL, Jonkman S, Koolhaas W, Stiekema A, Wolffenbuttel BH, Slart RH (2011) Combined vertebral fracture assessment and bone mineral density measurement: a new standard in the diagnosis of osteoporosis in academic populations. Osteoporos Int 22(4):10591068. doi:10.1007/s00198-010-1293-3

34. Kim SY, Schneeweiss S, Liu J, Daniel GW, Chang CL, Garneau K, Solomon DH (2010) Risk of osteoporotic fracture in a large population-based cohort of patients with rheumatoid arthritis. Arthritis Res Ther 12(4). doi: 10.1186/ar3107.

35. Wright NC, Lisse JR, Walitt BT, Eaton CB, Chen Z, Women's Health Initiative Investigators (2011) Arthritis increases the risk for fractures-results from the Women's Health Initiative. J Rheumatol 38(8):1680-1688. doi:10.3899/jrheum.101196

36. Weiss RJ, Wick MC, Ackermann PW, Montgomery SM (2010) Increased fracture risk in patients with rheumatic disorders and other inflammatory diseases - a case-control study with 53,108 patients with fracture. J Rheumatol 37(11):2247-2250. doi:10. 3899/jrheum. 100363

37. van Tuyl LH, Boers M, Lems WF, Landewé RB, Han H, van der Linden S, van de Laar M, Westhovens R, van Denderen JC, Westedt ML, Peeters AJ, Jacobs P, Huizinga TW, van de Brink H, Dijkmans BA, Voskuyl AE (2010) Survival, comorbidities and joint damage 11 years after the COBRA combination therapy trial in early rheumatoid arthritis. Ann Rheum Dis 69(5):807-812. doi: 10.1136/ard.2009.108027

38. Schett G, Kiechl S, Weger S, Pederiva A, Mayr A, Petrangeli M, Oberhollenzer F, Lorenzini R, Redlich K, Axmann R, Zwerina J, Willeit J (2006) High-sensitivity C-reactive protein and risk of nontraumatic fractures in the Bruneck study. Arch Intern Med 166(22):2495-2501

39. Oei L, Campos-Obando N, Dehghan A, Oei EH, Stolk L, van Meurs JB, Hofman A, Uitterlinden AG, Franco OH, Zillikens MC, Rivadeneira F (2014) Dissecting the relationship between high-sensitivity serum C-reactive protein and increased fracture risk: the Rotterdam Study. Osteoporos Int 25(4):1247-1254. doi: 10.1007/s00198-013-2578-0

40. Nakamura K, Saito T, Kobayashi R, Oshiki R, Oyama M, Nishiwaki T, Nashimoto M, Tsuchiya Y (2011) C-reactive protein predicts incident fracture in community-dwelling elderly Japanese women: the Muramatsu study. Osteoporos Int 22(7):2145-2150. doi:10.1007/s00198-010-1425-9

41. Ahmadi-Abhari S, Luben RN, Wareham NJ, Khaw KT (2013) Creactive protein and fracture risk: European prospective investigation into Cancer Norfolk Study. Bone 56(1):67-72. doi:10.1016/j. bone.2013.05.009

42. Ishii S, Cauley JA, Greendale GA, Crandall CJ, Danielson ME, Ouchi Y, Karlamangla AS (2013) C-reactive protein, bone strength, and nine-year fracture risk: data from the Study of Women's Health Across the Nation (SWAN). J Bone Miner Res 28(7):1688-1698. doi:10.1002/jbmr.1915

43. Wu ZJ, He JL, Wei RQ, Liu B, Lin X, Guan J, Lan YB (2015) Creactive protein and risk of fracture: a systematic review and doseresponse meta-analysis of prospective cohort studies. Osteoporos Int 26(1):49-57. doi:10.1007/s00198-014-2826-y

44. Hamada K, Nagai S, Tsutsumi T, Izumi T (1999) Bone mineral density and vitamin $\mathrm{D}$ in patients with sarcoidosis. Sarcoidosis Vasc Diffuse Lung Dis 16(2):219-223

45. Cremers JP, Drent M, Elfferich MD, Nelemans PJ, Wijnen PA, Witteman BJ, Schols AM (2013) Body composition profiling in a Dutch sarcoidosis population. Sarcoidosis Vasc Diffuse Lung Dis 30:289-299

46. Mostard RL, Prompers L, Weijers RE, van Kroonenburgh MJ, Wijnen PA, Geusens PP, Drent M (2012) F-18 FDG PET/CT for detecting bone and bone marrow involvement in sarcoidosis patients. Clin Nucl Med 37(1):21-25. doi:10.1097/RLU. ob013e3182335f9b

47. Liu B, Zhang X, Zhang W, Wang JB, Zhang FC (2012) Solitary osseous sarcoidosis: a rare reason for pathologic fracture. Rheumatol Int 32(8):2535-2538. doi:10.1007/s00296-010-1425-2

48. Levänen B, Wheelock AM, Eklund A, Grunewald J, Nord M (2011) Increased pulmonary Wnt (wingless/integrated)-signaling in patients with sarcoidosis. Respir Med 105(2):282-291. doi:10. 1016/j.rmed.2010.11.018 